\title{
Peat Stabilization by Using Sugarcane Bagasse Ash (SCBA) as a Partial Cement Replacement Materials
}

\author{
Nazatul Simaa Kamaruidzaman ${ }^{1}$, Mohd Khaidir Abu Talib, ${ }^{1,2,}$, Nurul Amirah \\ Alias ${ }^{1}$, Zainorabidin Adnan ${ }^{1,2}$, Aziman Madun ${ }^{1,2}$, Hazreek Zainal Abidin ${ }^{1}$, \\ Mohd Firdaus Md Dan ${ }^{1,2}$.
}

${ }^{1}$ Faculty of Civil and Environmental Engineering,

Universiti Tun Hussein Onn Malaysia, 86400 Parit Raja, Johor, MALAYSIA

${ }^{2}$ Research Centre of Soft Soil,

Universiti Tun Hussein Onn Malaysia, 86400 Parit Raja, Johor, MALAYSIA

*Corresponding Author

DOI: https://doi.org/10.30880/ijie.2019.11.06.022

Received 21 February 2019; Accepted 03 June 2019; Available online 31 August 2019

\begin{abstract}
Malaysia are covered approximately 2.6 million hectare of peat and facing serious geotechnical problems to develop infrastructure on peatland area. This study is to observe the basic geotechnical properties, strength and compressibility behavior of Pontian peat that stabilized by cement (OPC) and sugarcane bagasse ash (SCBA). The whole laboratory test standards and regulation that had been used in this study was adopted from American Society for Testing and Materials (ASTM) and British standards (BS). In order to understand an improvement of peat stabilization, unconfined compressive strength (UCS) and 1D-Oedometer consolidation test were conducted on untreated and stabilized peat. The results show that Pontian peat can be considered as hemic peat with average acidic. It was observed that the treated peat with 5\% of SCBA (PCB5) has the highest UCS of $190 \mathrm{kPa}$ and was discovered to be equivalent to PC specimen. There was a noteworthy decrease of void ratio, e for optimum PCB and PC mixtures as compared to untreated peat. The value of $\mathrm{C}_{c}$ and $\mathrm{C}_{\alpha}$ was quite low at small effective stresses, however it improved after beyond preconsolidation pressure, $\sigma^{\prime}{ }_{c}$. Compared to untreated Pontian peat which contributed the ratio of $C_{a} / C_{c}$ about 0.056, stabilized peat for PC and PCB5 gave better ratio with 0.0316 and 0.0273 respectively. Results shows that the treated peat $\mathrm{C}_{\alpha} / \mathrm{C}_{\mathrm{c}}$ ratios were drop dramatically from untreated peat which is representing the stabilized mixture can efficiently reduce the secondary compression.
\end{abstract}

Keywords: Peat stabilization, peat properties improvement, peat strength and compressibility.

\section{Introduction}

Malaysia covers about 2.6 million hectares of tropical peat deposits as shown in Fig. 1, where the accumulation and formation are favorable compared to the other tropics [1]. In term of country land area, Malaysia was ranked 10th in the world with 8\% [2]. Among these land, 6,300 hectares are found in Muar, Batu Pahat and Pontian in West Johor. Peat in the district of Pontian, have been developed to agricultural for oil palm, pineapple and other food crops [3]. Geotechnically, peat are classified as highly organic soil that having more than $75 \%$ of organic content which represent a problematic and poor quality of soil due to limited compressibility index [4]. Peat classification is important as they are weaker than inorganic soil that subsequently lead to instability and long term settlement when subjected to load [5].

Sugarcane industries contribute to 1.9 billion tons of by-products where one metric ton of sugarcane creates $280 \mathrm{~kg}$ bagasse [6]. The utilization of sugarcane bagasse that were mainly utilized as to fuel sugar mill leave the bagasse ash as 
waste. Disposal issue for the bagasse creates serious concern as it pollutes the environment. Sugarcane industries proposed to use this ash as fertilizer-in the plantation, but this ash does not provide sufficient mineral nutrient for the growth of the plantation. To dispose the waste generated, industries are yet still looking for the answers for this issue [7]. In the recent years, there are researchers who detect the competence of the cement in the stabilization of peat soil [4, 814]. It was found that highly organic soil can delay or prevent the proper hydration of cement in binder-soil mixtures [10].

As consequence of high organic content and less solid particles in peat soil, the used of cement alone as a chemical admixture is not sufficient to stabilize peat. That means, the large quantity of cement is required with the purpose of acids neutralization or otherwise the process of the peat stabilization remains retarded. Moreover, considering the fact that peatland encompass a wide area, the large cement consumption and its transportation to the site will become an unfriendly and uneconomical answer to peat improvement [15]. Cement is contributing about $5 \%$ to $8 \%$ of worldwide carbon oxide, $\mathrm{CO}_{2}$ emissions and expected to up to raise 0.8 to $1.2 \%$ per year until could reach 4.4 billion tonnes in 2050 [16].

In recent years, utilization of SCBA in stabilized peat were studied extensively. The results indicate the capability of SCBA as to partially replace the cement quantity in peat stabilization. It was found the SCBA percentages could extent up to $20 \%$ of cement replacement on Japan peat [17-22]. This paper presents an effect of SCBA that used as a cement replacement material on Pontian peat in Johor, Malaysia.
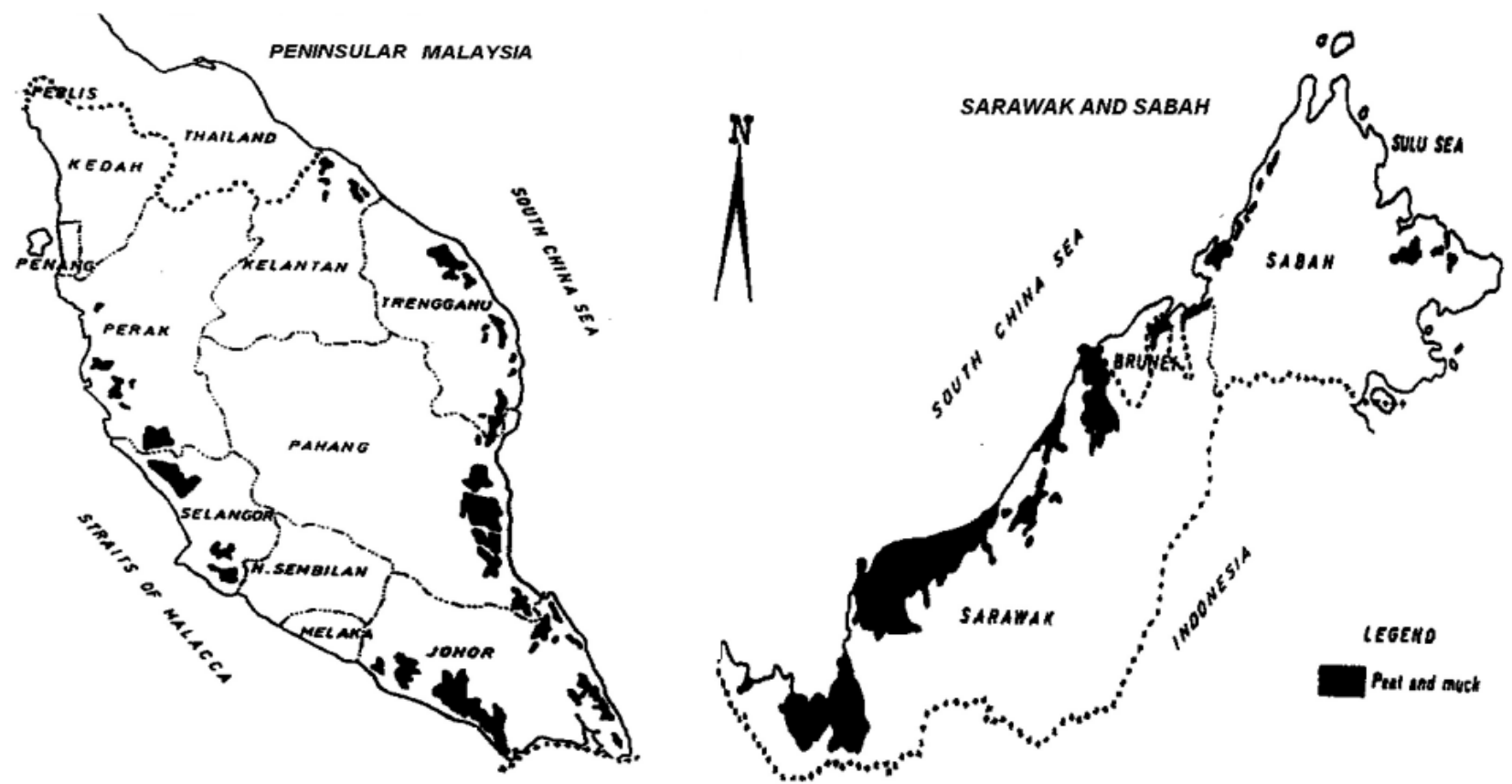

Fig. 1 - Distribution in Peninsular Malaysia.

\section{Experimental Studies}

This research required the use of peat soil, Sugarcane Bagasse Ash (SCBA), Ordinary Portland Cement (OPC) and calcium chloride $\left(\mathrm{CaCl}_{2}\right)$. The entire mix designs of stabilized peat for laboratory test are presented in Table 1 . Peat soil sample were collected from Pontian district in West Johor. To avoid any particles from surface included in the process of collecting the samples, top soil of the site area was removed about 0.1 to $0.2 \mathrm{~m}$ from the surface and samples were obtained in depth 0.3 to $1 \mathrm{~m}$. Polyvinyl chloride (PVC) tubes with $100 \mathrm{~mm}$ diameter and $200 \mathrm{~mm}$ in height were used to collect Undisturbed sample of peat soil. The bottom of the PVC tubes was sharped to make sure that the tube was easier to press into the ground and cuts all the organic materials during sampling process. To preserve the moisture content of the peat sample, the PVC tube were then taken out properly and sealed with wax at both ends and wrapped with aluminum foils and plastics film. Sugarcane bagasse were collected from sugarcane juice traders in Parit Raja area and were dried naturally before blending the bagasse. The ash was produced by drying the bagasse in furnace at $500^{\circ} \mathrm{C}$ for 5 hours.

The test of physical, mechanical and chemical properties of these peats had been conducted as shown in Fig. 2. American Society for Testing and Materials (ASTM) standards were adopted and implemented as a guideline in the whole laboratory test regulation as shown in Table 2 [23] and British Standards (BS). In order to elucidate the stabilized peat strength improvement, unconfined compressive strength (UCS) and 1D-Oedometer tests were conducted. UCS is defined as the compressive stress $\left(\mathrm{q}_{\mathrm{u}}\right)$ at which an unconfined cylindrical specimen of soil will fail in a simple compression test [24]. For untreated peat, mould size of $50 \mathrm{~mm}$ diameter and $100 \mathrm{~mm}$ length were used to prepare the specimen in three layers. 10 full thumb pressure were subjected to each layer at about 10 seconds per layer [9]. 
Table 1 - Stabilized peat mix designs for laboratory testing.

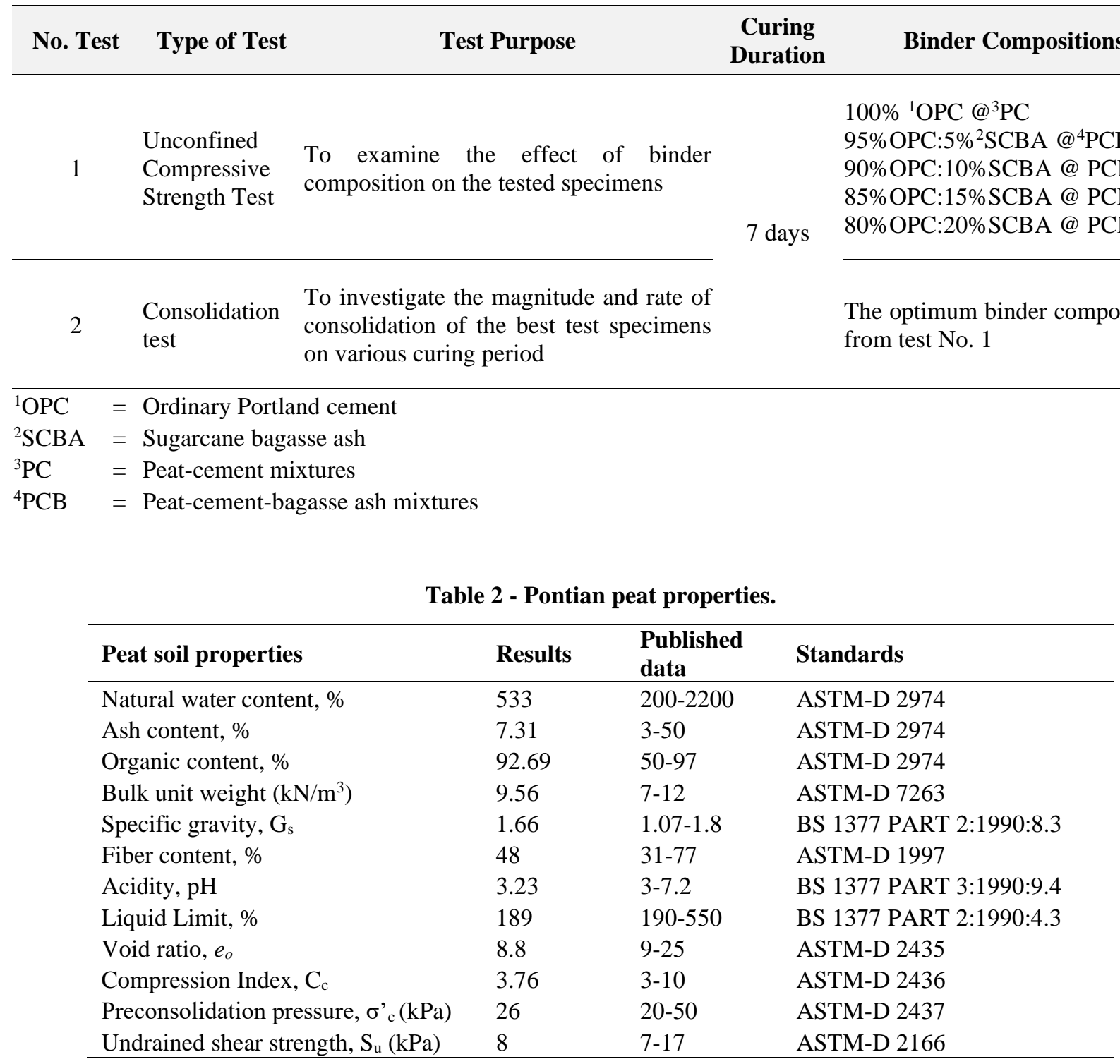

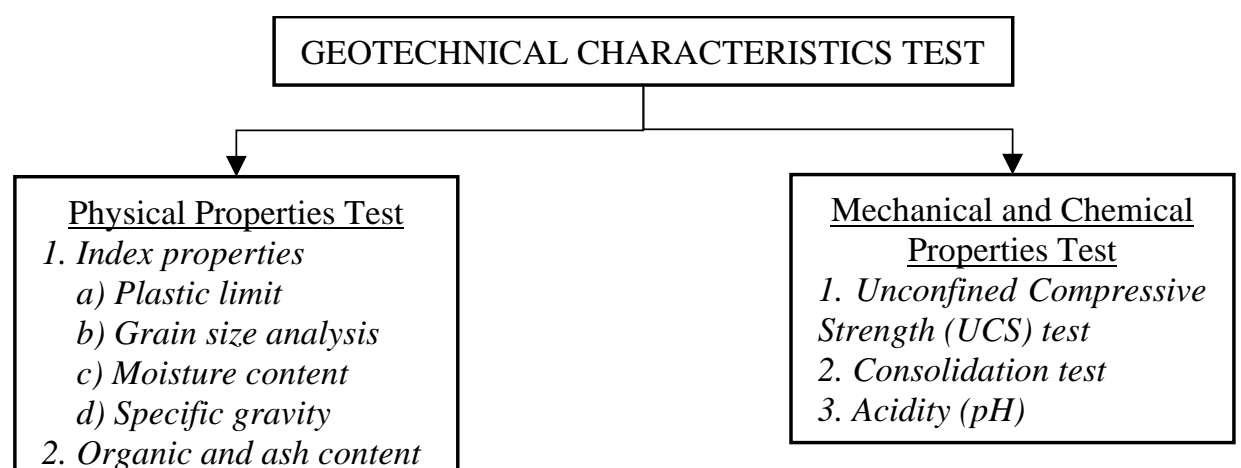

Fig. 2 - Geotechnical characteristics laboratory tests. 
Afterward, the samples were extruded, and the test specimen was cut to the needed size for testing. The 1DOedometer tests were perform by using six incremental load stages and each load stage lasted 24 hours on the untreated peat, optimum PCB5 and PC mixtures that obtained from UCS test. The size of specimens was 50 mm in diameter and $20 \mathrm{~mm}$ in height. An initial stress of $12.5 \mathrm{kPa}$ was applied and the stress was increased in steps at the end of each load stage using a load increment ratio of unity until a final stress of $400 \mathrm{kPa}$ had been applied. In the direction of the peat improvement assessment, the proved parameters of the stabilized peat soil should be compared to untreated peat.

\section{Results and Discussion}

\subsection{Material Properties}

The typical evaluation of basic properties for untreated peat were expose in Table 2 . In order to verify the reliability of obtained results, the basic properties ranges for typical West Malaysia peat were grouped from published data [1, 2527] for the use of guidance purpose. Peat sample were left dry at $105^{\circ} \mathrm{C}$ about 24 hours to determine the moisture or natural water content. Sample were left ignited in oven-dried muffle furnace at $440^{\circ} \mathrm{C}$ about 7 hours (until no change in mass) to determine the ash content of the sample. The ratio from the oven dried sample mass, express the ash content. Organic matter was calculated by subtracting the percent of ash content from one hundred. Dispersing agent (5\% sodium hexametaphosphate) was used to submerge the peat soil sample for about $15 \mathrm{~h}$ to determine the fiber content of the peat soil. Washed through the material below a gentle tap water by using a 100-mesh $(150 \mu \mathrm{m})$ sieve. The fibrous material that retained on the sieve was oven-dried $\left(\right.$ at $\left.105^{\circ} \mathrm{C}\right)$ until a constant mass is achieved. The mass of fiber is determined from the percentage of the oven-dried mass of the original sample.

From the findings in Table 2, it can be seen that the peat has fiber content between $31 \%$ and $77 \%$, ash content higher than $3 \%$ while the $\mathrm{pH}$ value at 3.23. As a result, this peat can be characterized as hemic peat with high ash and average acidic [23]. Natural water content can be extended from 200 to $700 \%$ with 50 to $95 \%$ organic content range for tropical hemic peat of west Malaysia (Figure 3). With the increasing of natural water content ( $w \%$ ), the organic content (OC \%) were increased. The $w$ and OC for Pontian peat (Parit Markom) are in the range for West Malaysia peat as exposed in Table 2 and Fig. 3. It is discovered that the studied peat revealed a high compressibility and instability characteristics that influenced by high compression index, void ratio, water content, liquid limit that eventually affecting in low shear strength of the peat soil sample.

The unconfined compressive strength (UCS) and 1D-Oedometer tests were conducted with the purpose to clarify the stabilized peat strength improvement. The UCS result for untreated peat shows the peak was not obtained until $20 \%$ of axial strains. Hence, the max value of UCS was taken at $15 \%$ of strain which is equal to $10 \mathrm{kPa}$. Based from the experimental testing result, undrained shear strength, $\left(S_{u}=q_{u} / 2\right)$ was equal to $5 \mathrm{kPa}$. These values specify that Pontian peat is extremely soft. Casagrande's graphical method were used to identify the compression index, $\mathrm{C}_{\mathrm{c}}$ from the difference of the void ratio e, $\Delta \mathrm{e}$ as an element of the difference in effective vertical stress, $\sigma_{\mathrm{v}}$ plotted in the logarithmic scale, $\mathrm{C}_{\mathrm{c}}=\Delta \mathrm{e} /\left(\Delta \log \sigma_{\mathrm{v}}\right)$ while developing the preconsolidsation pressure, $\sigma_{\mathrm{c}}$.

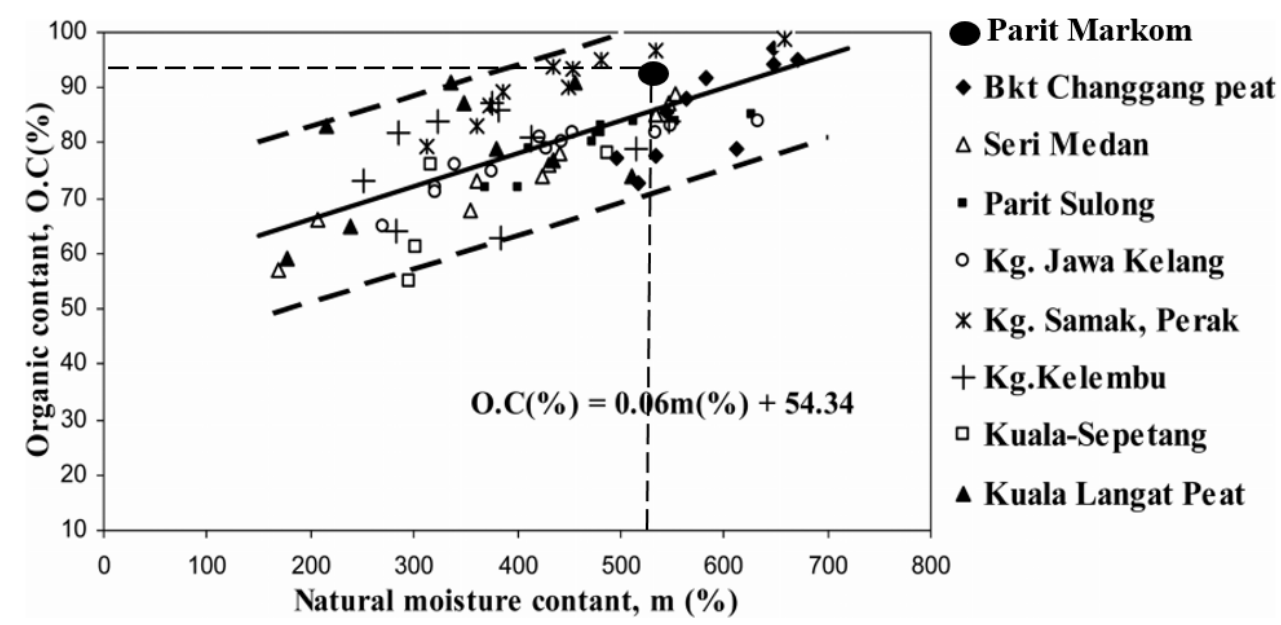

Fig. 3 - Water content versus organic content [25].

\subsection{Effect of SCBA Replace Partially of OPC on The Strength Characteristics}

Partial replacement of cement with SCBA that differs in amount from 5\% to $20 \%$ (Table 1), indicate the ideal UCS based on the result of UCS test of stabilized peat in Fig. 4. It proved that UCS experimental testing results of the stabilized peat have influence by the SCBA as a percentage replacement of OPC. It is obviously identified from the test specimen 
with $5 \%$ partial replacement of OPC with SCBA (PCB5) have the maximum UCS value with $190 \mathrm{kPa}$, slightly more than UCS of PC specimen (C100). Commonly, when cement react with water $\left(\mathrm{H}_{2} \mathrm{O}\right)$, Calcium silicate hydrates $(\mathrm{CSH})$ or otherwise called tobermorite gels together with calcium hydroxide $(\mathrm{CH})$ are produced. Bonding agent that ties and bind the soil particles together are from the CSH. However, humic acid in peat responds with calcium ion to produce insoluble calcium humic acid.

The low strength gain in the soil-cement mixture are restrained and renders from the condition of secondary pozzolanic reaction amongst $\mathrm{CH}$ and peat. Condition where ideal effect of cement hydration have completed, this may be explained that the value of UCS for PCB5 are better. The addition of SCBA in the soil-cement mixture method, improved the hydration of cement to create more secondary tobermorite gels beside with calcium alumina silicate hydrates (CASH) when pozzolan responds with calcium hydroxide and water. An alkaline atmosphere that increase the secondary pozzolanic reaction within the cemented soil are created from the pozzolan which contains extra silica and alumina that activated by cement is able to equalize the acid is likely the main reason. Therefore, the additional CSH and CASH densify the stabilized peat and improving its strength [15].

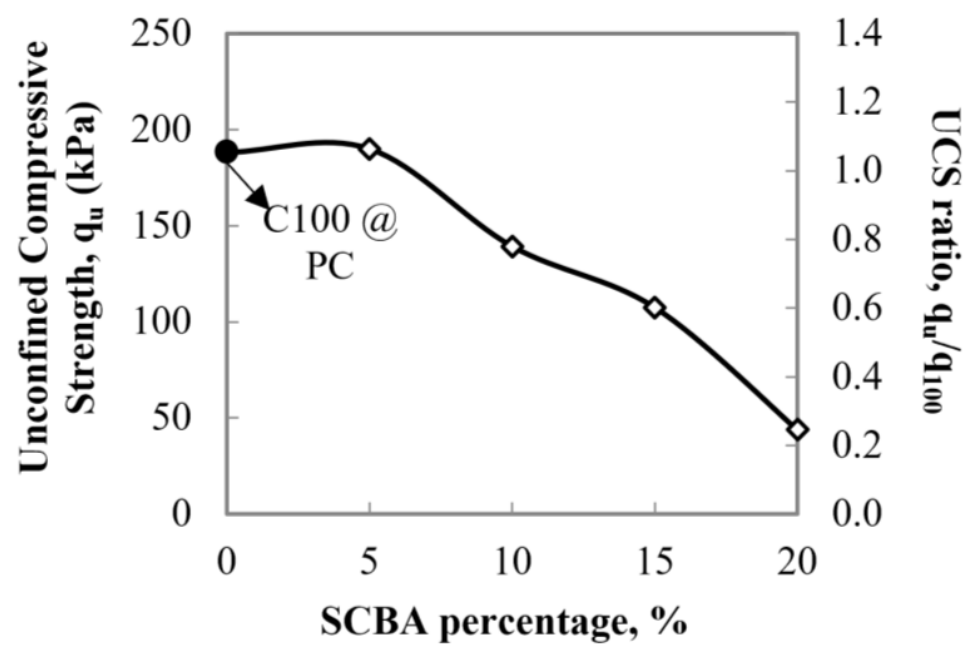

Fig. 4 - Effect of SCBA percentage replacement on the UCS on stabilized peat.

\subsection{Effect of Partial Replacement of OPC with SCBA on the Deformation Characteristic}

Fig. 5 and Fig. 6 show the void ratio, e versus effective vertical stress, $\sigma^{\prime}{ }_{v}$ for untreated and stabilized peat (PC and PCB5) results presented in graphical illustration. Untreated peat exposed the high e and $\mathrm{C}_{\mathrm{c}}$ with about 8.8 and 3.76 respectively. This is a result as plant matters that rearrange peat particles are light and hold an extensive water volume. Besides, the specific gravity of organic matter is relatively small and the porous particle influencing the light peat grains, plates and fibre component. Hence, the high value of compression index, $\mathrm{C}_{\mathrm{c}}$ are the result from the high in e, of peat deposits [28]. Void ratio, e in stabilized peat shows a significant reduction compared to untreated peat (Fig. 6). Peat stabilization should significantly reduce the void ratio thus and so its permeability [15]. This figure also illustrates that towards moving the increasing of preconsolidation pressure, $\sigma^{\prime}{ }_{c}$ of stabilized peat, the compression behaviour were affected. Untreated peat increased from $25 \mathrm{kPa}$ to about $51 \mathrm{kPa}$ and $63 \mathrm{kPa}$ on $\sigma_{\mathrm{c}}$ for PC and PCB5 respectively. As a result of increasing in value of $\sigma_{\mathrm{c}}$, higher effective stress shifting the compression curve of the stabilized peat. These effect are the indication of the effectiveness of peat stabilization in improving settlements [29].

Fig. 7 displays the coefficient of volume compressibility, $m_{v}=\left[\left(\Delta H / H_{a v g}\right) \% x \Delta P\right]$ versus effective vertical stress, $\sigma^{\prime}{ }_{\mathrm{v}}$ of Pontian peat. The results illustarate that the decreasing in coefficient of permeability are affected from the additional of consolidation pressure. The $\mathrm{m}_{\mathrm{v}}$ a little higher at the lower range of pressure but were drastically decreased less towards reaching larger compression. Hence, the bonding between bagasse and cement with soil particle developing a hardened skeleton matrix and improved the soil compressibility. This pattern is in concurrence with the consolidation theory [3, 30]. Kazemian and Huat [31] specified that, the estimation of primary consolidation settlement with this consolidation theory parameter is very suitable. Thus, soil settlement potential reduced with lower $\mathrm{m}_{\mathrm{v}}$.

The variation of $\mathrm{C}_{c}$ and $\mathrm{C}_{\alpha}$ with applied effective stress of the stabilized peat are as illustrate in Fig. 8. $\mathrm{C}_{c}$ and $\mathrm{C}_{\alpha}$ are relatively lower at low effective stresses, however, start to become greater when vertical pressure increased. It is discovered that the creep that related with a structural failure have an association to the significant increase in $\mathrm{C}_{\alpha}$ happens after yielding on the stabilized peat [10]. It was assumed that secondary compression starts 4 hours after loading, making an allowance for the standard oedometer apparatus used in this research could not estimate the dissipation of water throughout the consolidation. For that reason, after 4-24 hours load incremental was applied, $\mathrm{C}_{\alpha}=\Delta \mathrm{e} /(\Delta \log \mathrm{t})$ for 
stabilized peat was determined from the illustration of graph on slope of the e vs log t curve. This theory are applied from previous research conducted by Hebib and Farrel [10] and Duraisamy [32].

Fig. 9 illustrate the compression index ratio, $\mathrm{C}_{\alpha} / \mathrm{C}_{\mathrm{c}}$ for untreated and stabilized peat of different binders. Previous researcher proposed a range of $\mathrm{C}_{\alpha} / \mathrm{C}_{c}=0.06 \pm 0.01$ for natural peat deposits [28]. Less compressible soil indicates lesser ratio of $\mathrm{C}_{\alpha} / \mathrm{C}_{\mathrm{c}}$. It was observed that $\mathrm{C}_{\alpha} / \mathrm{C}_{\mathrm{c}}$, for untreated peat in this study was 0.056 , which is included in the suggested range. On the other hand, $\mathrm{C}_{\alpha} / \mathrm{C}_{\mathrm{c}}$ for $\mathrm{PC}$ and $\mathrm{PCB} 5$ were at 0.0316 and 0.0273 respectively. Hence, stabilize peat produce less creep settlement when associated to untreated peat. The result for $\mathrm{C}_{\alpha} / \mathrm{C}_{\mathrm{c}}$ ratio was a little higher in stabilize PC mixture if compared to stabilized PCB5 mixtures. This could be explained by the fact that the soil is PCB5 mixture structure are finer and have a better quality than PC mixture ever since the particle have fully filling the void. In other words, the finer and better quality of the mixture structure, the lesser the $\mathrm{C}_{\alpha} / \mathrm{C}_{\mathrm{c}}$ ratio which indicate that stabilized peat was less compressible [20].

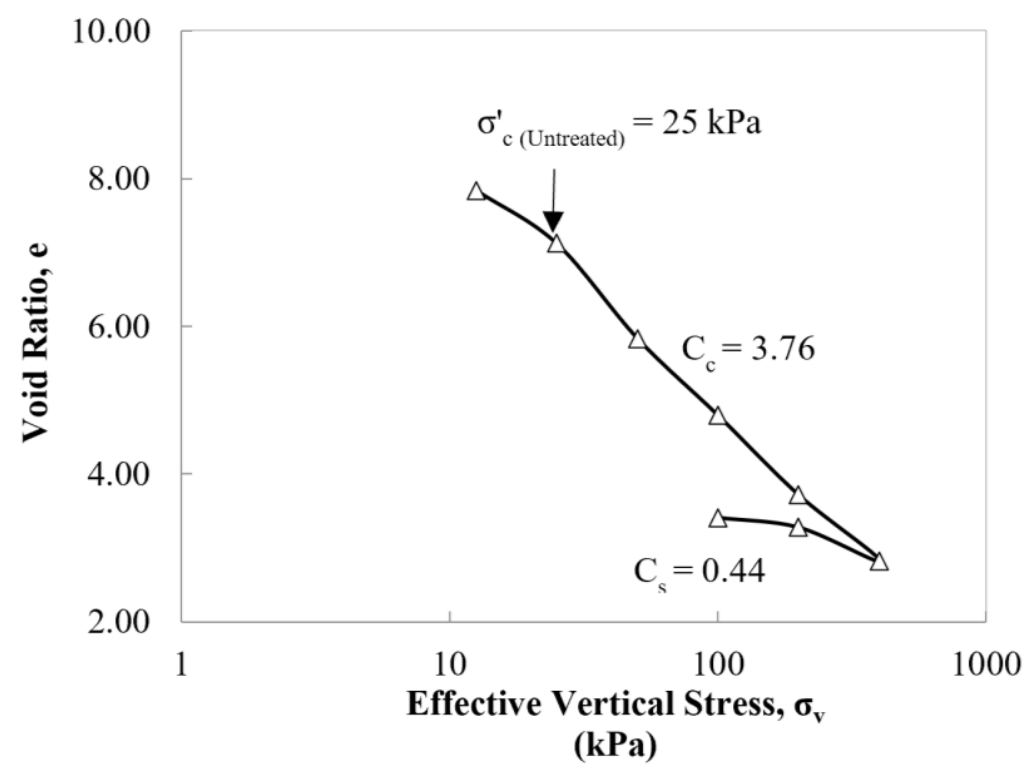

Fig. 5 - Void ratio (e) versus effective vertical stress $\left(\sigma_{v}\right)$ for untreated peat.

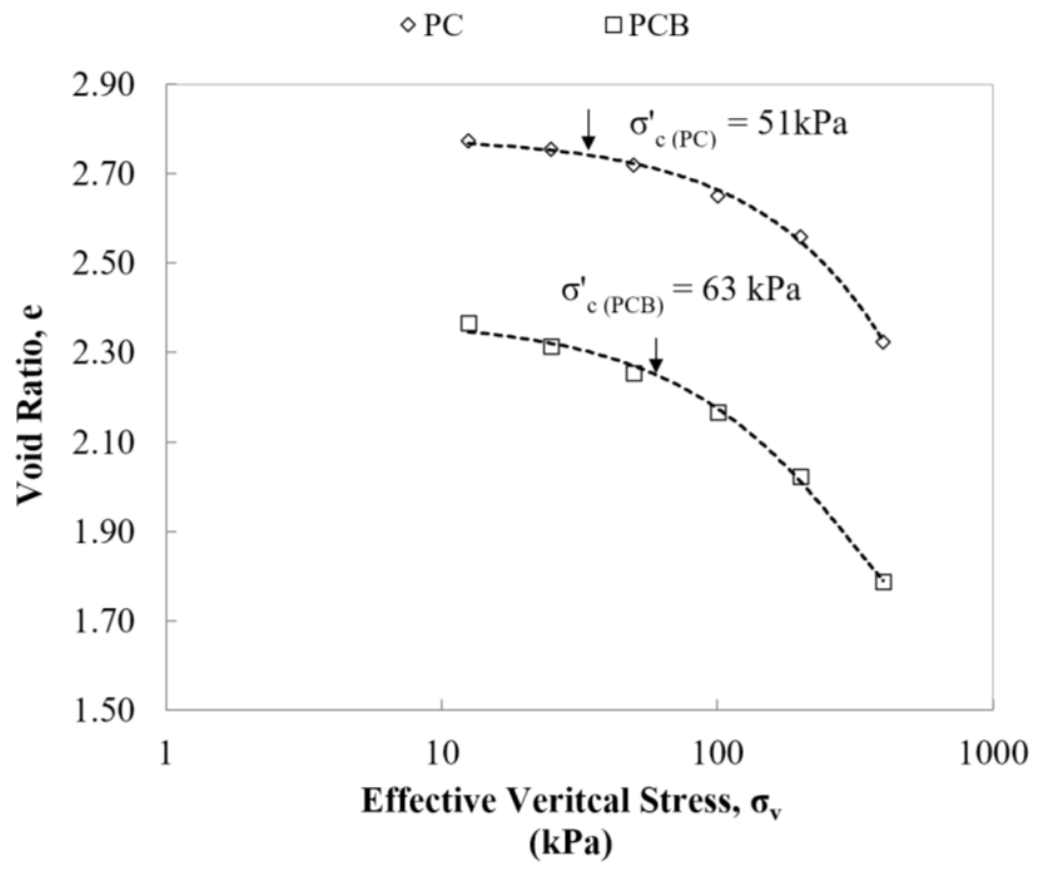

Fig. 6 - Void ratio (e) versus effective vertical stress $\left(\sigma_{v}\right)$ for stabilized peat. 


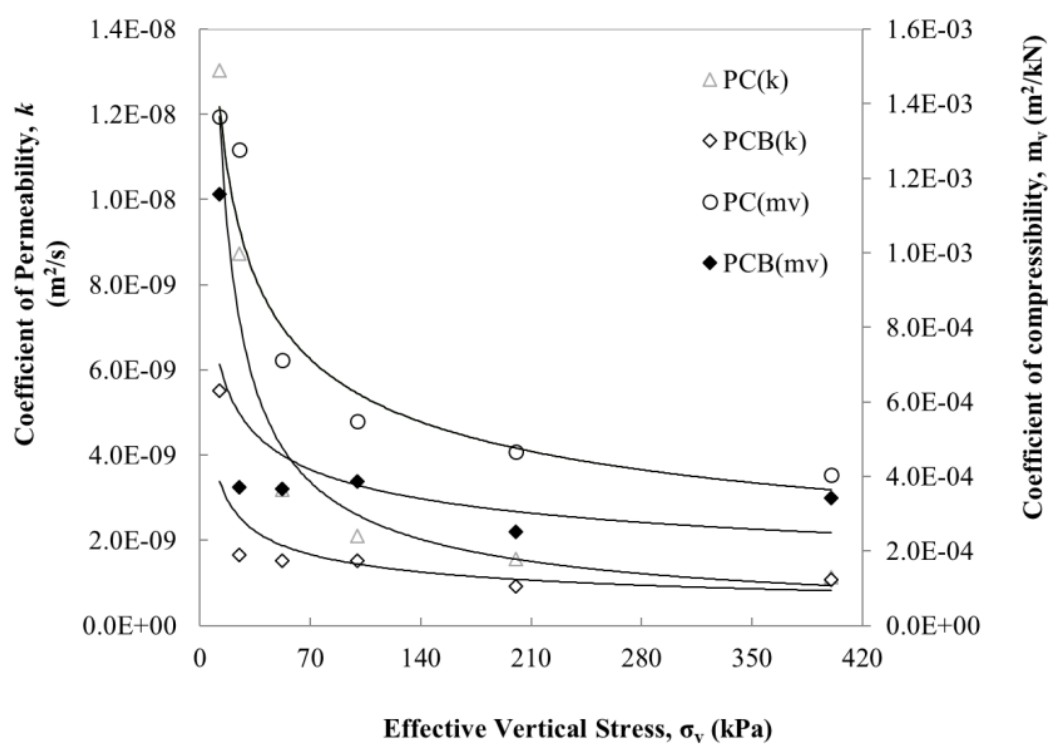

Fig. 7 - Coefficient of volume compressibility, $\mathbf{m}_{v}$, versus effective vertical stress $\left(\sigma_{v}\right)$ for stabilized peat.

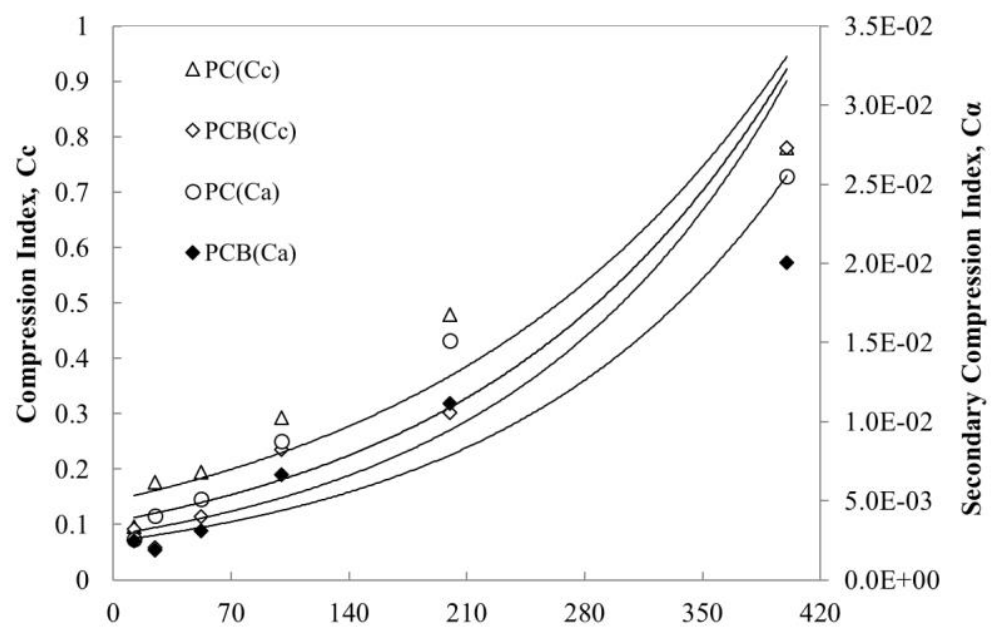

Effective Vertical Stress, $\sigma_{\mathrm{v}}(\mathrm{kPa})$

Fig. 8 - The variation of $\mathrm{Cc}$ and $\mathrm{C} \alpha$ with effective vertical stress for stabilized peat.

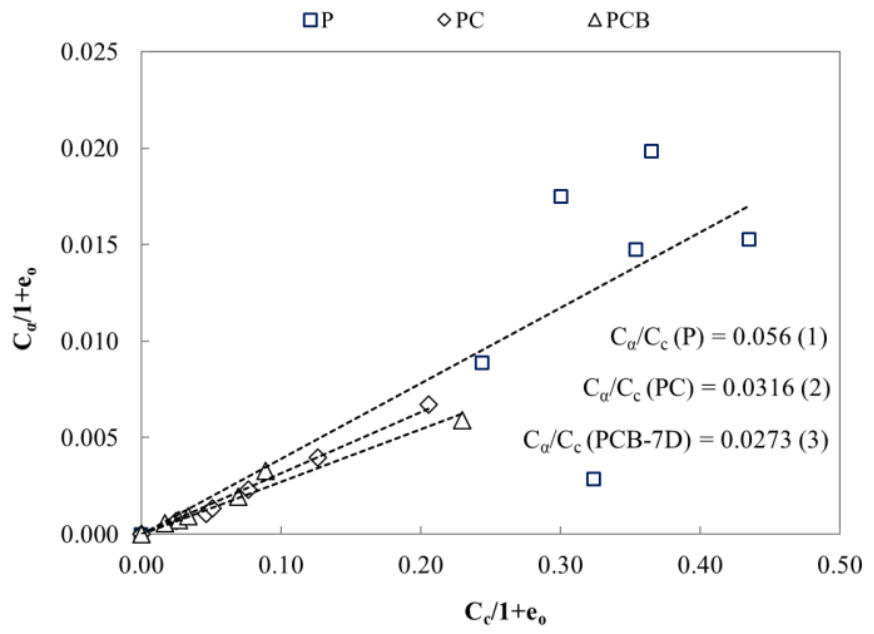

Fig. 9 - $C_{a}$ ratio versus $C_{c}$ ratio with different binders. 
The $\mathrm{C}_{\alpha} / \mathrm{C}_{\mathrm{c}}$ ratios and UCS were plotted in contrast to different mixtures as illustrate in Fig. 10. From the soil engineering behavior, it is known from peaty or organic soils shifting to inorganic soils and finally to a granular material towards the decreasing of $\mathrm{C}_{\alpha} / \mathrm{C}_{\mathrm{c}}$ ratio $[14,20,29,33,34]$. It is found that $\mathrm{C}_{\alpha} / \mathrm{C}_{\mathrm{c}}$ ratios for PCB stabilized peat mixture extended and have improved to granular soil materials. Improvements were observed and the pattern illustrate were similar to UCS results which were noticeably small. The compression index ratio, $\mathrm{C}_{\mathrm{c}} / 1+\mathrm{e}_{\mathrm{o}}$ are as displayed in Fig. 11. By referring to the classification of compression index ratio in Table 3 [32], $\mathrm{C}_{\mathrm{c}} / 1+\mathrm{e}_{\mathrm{o}}$, the compressibility level could be classified [35]. Compressibility behavior of untreated peat was revealed to have a significant change form very compressible to slightly compressible. It was revealed that PCB5 shows the less compressibility compare to PC stabilized peat with $\mathrm{C}_{\mathrm{c}} / 1+\mathrm{e}_{\mathrm{o}}=0.0877$ and hugely decreased as much as $51 \%$ from untreated peat $\left(\mathrm{C}_{\mathrm{c}} / 1+\mathrm{e}_{\mathrm{o}}=0.3398\right)$. These results are reliable and replicated to be an good foundation material by the geotechnical and pavement engineers, since the compression behavior of organic soils give the impression to be fundamentally shifting to granular soil and slightly compressible [14].

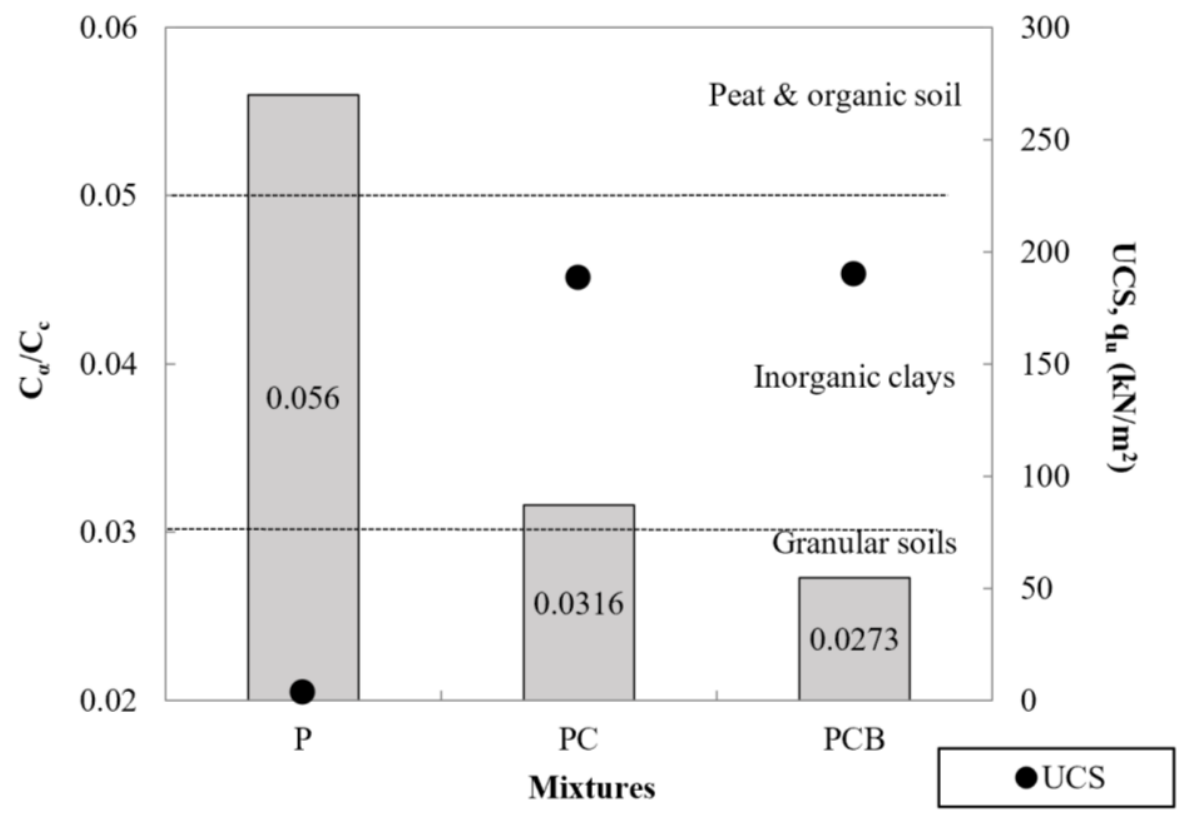

Fig. 10 - $C_{\alpha} / C_{c}$ ratio with different binders.

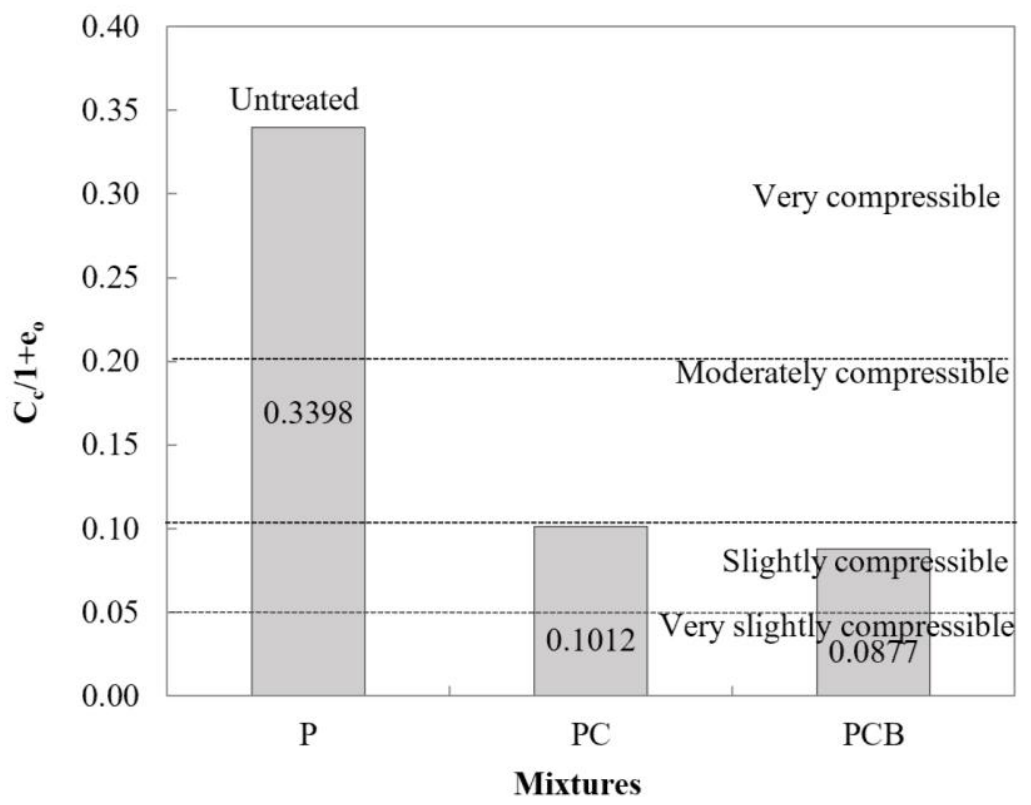

Fig. 11 - Compression ratio, $\mathrm{C}_{\mathrm{c}} / 1+\mathrm{e}_{\mathrm{o}}$ with different binders. 
Table 3 - Classification of compression ratio [32].

\begin{tabular}{cc}
\hline Compression ratio $(\mathbf{C} \mathbf{c} / \mathbf{1}+\mathbf{e})$ & Classification \\
\hline $0-0.05$ & Very slightly compressible \\
$0.05-0.10$ & Slightly compressible \\
$0.10-0.20$ & Moderately compressible \\
$>0.20$ & Very compressible \\
\hline
\end{tabular}

\section{Conclusion}

Stabilized peat by using the utilization of sugarcane bagasse ash as to replace cement has been examined. It can be precisely showing that the mechanical properties in stabilized peat by the utilization of SCBA were markedly improved. Base on the analysis, data and explanation obtain in this paper, the subsequently conclusion are made. Pontian peat can be considered as hemic peat with high ash and average acidic. It was observed that the test specimen with $5 \%$ partial replacement of OPC with SCBA has the uppermost UCS of $190 \mathrm{kPa}$ and was discovered to be as good as to PC specimen. There was a major decrease of void ratio, e for optimum PCB and PC mixtures as associated to untreated peat.

The value of $\mathrm{C}_{\mathrm{c}}$ and $\mathrm{C}_{\alpha}$ was somewhat low at small effective stresses, however it bigger as preconsolidation pressure, $\sigma_{c}^{\prime}$ was approached and continuous to rise after beyond these pressures. Compared to untreated Pontian peat which contributed the ratio of $\mathrm{C}_{\alpha} / \mathrm{C}_{\mathrm{c}}$ about 0.056 , stabilized peat for $\mathrm{PC}$ and PCB5 gave better ratio with 0.0316 and 0.0273 individually. Results outcome illustrate that the stabilized peat $\mathrm{C}_{\alpha} / \mathrm{C}_{\mathrm{c}}$ ratios were decline affectedly from untreated peat which is specifying that the stabilized mixture can efficiently decrease the secondary compression.

Finally, it is suggested that the gained optimum mix design can be applied to stabilized shallow peat layer in order to support road embankment. The encouraging results from this research work is attributed to the activities among the cement hydration, the pozzolanic reaction and filler effect of SCBA that complemented with silica sand in the stabilized peat.

\section{Acknowledgement}

The authors gratefully acknowledge use of the services and facilities of the Geotechnical Laboratory and Research center of Soft Soil (RECESS) at the Universiti Tun Hussein Onn Malaysia (UTHM), funded by UTHM Grant (TIER 1U840).

\section{References}

[1] Tang, B.L., Bakar, I., \& Chan, C.M. (2011). Reutilization of organic and peat soils by deep cement mixing. International Journal of Civil and Environmental Engineering, 5(2), 87-92.

[2] Hartlen, J. \& Wolski, J. (1996). Embankments on organic soils ( $1^{\text {st }}$ Ed.). Amsterdam: Elsevier.

[3] Yulindasari, I. (2006). Compressibility Characteristics of Fibrous Peat Soil. Master Dissertation. Universiti Teknologi Malaysia.

[4] Wong, L.S., Roslan, H. \& Ali, F.H. (2008). Engineering behaviour of stabilized peat soil. European Journal of Scientific Research, 21(4), 581-591.

[5] Jarrett, P.M. (1995). Site investigation for organic soils and peat. Geoguide 6. JKR Document 20709-0341-95. (Malaysia: Public Works Department Malaysia). Geoguide, 6:4-16.

[6] Sun, J.X., Sun, X. F., Sun, R. C. \& Su, Y. Q. (2004). Fractional extraction and structural characterization of sugar cane bagasse hemicelluloses. Carbohydrate Polymers, 56, 195-204.

[7] Sales, A. \& Lima, S.A. (2010). Use of Brazilian sugarcane bagasse ash in concrete as sand replacement. Waste Management, 30(6), 1114-1122.

[8] EuroSoilStab. (2002). Development of design and construction methods to stabilize soft organic soils. Design guide soft soil stabilization. CT97-0351. Project No. BE 96-3177, Industrial \& Materials Technologies Programme (BriteEuRam III), European Commission: 94 pages.

[9] Axelsson, K., Johansson, S.E. \& Anderson, R. (2003). Stabilization of Organic Soils by Cement and Puzzolanic Reactions - Feasibility Study, (Swedish deep stabilization Research Centre: Sweden), Report 3: pp 52. English translation.

[10] Hebib, S. \& Farrell, E.R. (2003). Some experiences on the stabilization of Irish peats. Canadian Geotechnical Journal, 40(1), 107-120.

[11] Huat, B.K., Maail, S., \& Mohamed, T.A. (2005). Effect of chemical admixtures on the engineering properties of tropical peat soils. American Journal of Applied Sciences, 2(7), 1113-1120. 
[12] Chen, H. \& Wang, Q. (2006). The behaviour of organic matter in the process of soft soil stabilization using cement. Bulletin of Engineering Geology and the Environment,65(4), 445-448.

[13] Ahnberg, H. (2006). Strength of stabilised soils- A laboratory study on clays and organic soils stabilised with different types of binder, (Swedish deep stabilization Research Centre: Sweden), Report 16: pp 80. English translation.

[14] Sobhan, K., Reddy, D.V., \& Ramirez, J.C. (2012). Cement stabilization of organic subgrades for pavement preservation, in megaprojects: Building infrastructure by fostering engineering collaboration, efficient and effective integration and innovative planning (Panama City: Panama), 1-10.

[15] Wong, L.S., Hashim, R., \& Ali, F.H. (2009). A review on experimental investigations of peat stabilization. Australian Journal of Basic and Applied Sciences, 3(4), 3537-3552.

[16] WBCSD, Cement Technology Roadmap 2009. (2009). World Business Council for Sustainable Development, W.B.C.S.D. (France: International Energy Agency, I.E.A), 31 pages.

[17] Abu Talib, M.K., Yasufuku, N., \& Ishikura, R. (2017). Utilization of sugarcane bagasse ash in peat stabilization. 9th International Symposium on Lowland Technology (Saga: Japan), 174-180.

[18] Talib, M.K.A. (2017). Highly Organic Soil Stabilization by Using Sugarcane Bagasse Ash (SCBA). MATEC Web of Conferences 103, 07013.

[19] Talib, M.K.A., Yasufuku, N., \& Ishikura, R. (2015). Effectiveness of sugarcane bagasse ash (SCBA) as partial cement replacement in peat stabilization. Memoirs of the Faculty of Engineering (Kyushu University: Japan), 74(3).

[20] Talib, M.K.A., Yasufuku, N., \& Ishikura, R. (2014). An Overview on Japan and Malaysia peat relating to geotechnical characteristic. International Journal of Integrated Engineering, 6(1), 1-7.

[21] Talib, M.K.A., Yasufuku, N., \& Ishikura, R. (2015). Effects of sugarcane bagasse ash (SCBA) on the strength and compressibility of cement stabilized peat. Lowland Technology International 2015. International Association of Lowland Technology (IALT), 17(2), 73-82.

[22] ASTM. (2005). American Society of Testing Materials, Annual Book of ASTM Standards, Soil and Rock (I): D 420 - D 5611 (Pennsylvania: ASTM), 04.08.

[23] ASTM-D2166. (2005). Standard test method for unconfined compressive strength of cohesive soil. American Society for Testing and Materials Standards (Pennsylvania: ASTM) 04.08.

[24] Huat, B.K., Sew, G.S., \& Ali, F.H. (2004). Organic and peat soils engineering, (Serdang: University Putra Malaysia Press), 146.

[25] Zainorabidin, A., \& Wijeyesekera, D.C. (2008). Geotechnical characteristics of peat. Proceedings of the AC\&T (University of East London), $71-78$.

[26] Zainorabidin, A., Wijeyesekera, D.C., \& Mohd Masirin, M.I. (2007). Comparative study of British and Malaysian peat soils pertaining to geotechnical characteristics. Sri lankan Geotechnical Society and ISSMGE (Tucson: University of Arizona), 252-261.

[27] Mesri, G., Stark, T.D., Ajlouni, M.A., \& Chen, C.S. (1997). Secondary compression of peat with or without surcharging. Journal of Geotechnical and Geoevironmental Engineering, 123(5), 411-421.

[28] Bobet, A., Hwang, J., Johnston, C.T., \& Santagata, M.C. (2011). One-dimensional consolidation behavior of cement-treated organic soil. Canadian Geotechnical Journal, 48(7), 1100-1115.

[29] Gofar, N. (2006). Determination of coefficient of rate of horizontal consolidation of peat soil. Master Dissertation (Malaysia: Universiti Teknologi Malaysia), 36-172.

[30] Kazemian, S., Asadi, A., \& Huat, B.K. (2009). Laboratory study on geotechnical properties of tropical peat soils. International Journal of Geotechnics and Environment, 1, 69-79.

[31] Duraisamy, Y., Huat, B.K., \& Ratnasamy, M. (2008). Compressibility Behavior of Fibrous Peat Reinforced with Cement Columns. ICCBT- E- (09), 93-110.

[32] Mesri, G., Stark, T.D., \& Chen, C.S. (1994). Cc/C $\alpha$ concept applied to compression of peat. Discussion. Journal of Geotechnical and Geoenvironmental Engineering, 120, 764-766.

[33] Hwang, J., Humphrey, A., Bobet, A., \& Santagata, M.C. (2005). Stabilization and improvement of organic soils. Publication FHWA/IN/JTRP-2004/38. Joint Transportation Research Program, Indiana Department of Transportation and Purdue University (West Lafayette: Indiana), 270.

[34] Loughlin, C.D., \& Lehane. B.M. (2003). A Study of the link between composition and compressibility of peat and organics soil. Proceedings of 2nd International Conference on Advances in Soft Soil Engineering and Technology (Malaysia: Putrajaya), 135-152. 